PAPER

\title{
Functional analysis of a recurrent missense mutation in Notch3 in CADASIL
}

\author{
T Haritunians, T Chow, R P J De Lange, J T Nichols, D Ghavimi, N Dorrani, D M St Clair, \\ G Weinmaster, C Schanen
}

J Neurol Neurosurg Psychiatry 2005;76:1242-1248. doi: 10.1136/jnnp.2004.051854

See end of article for authors' affiliations

.....................

Correspondence to: Dr C Schanen, Nemours Biomedical Research, Alfred I duPont Hospital for Children, 1600 Rockland Road, Wilmington, DE 19803, USA; schanen@ medsci.udel.edu

Received 11 August 2004 In revised form 3 December 2004

Accepted 3 January 2005

\begin{abstract}
Background: Cerebral autosomal dominant arteriopathy with subcortical infarcts and leukoencephalopathy (CADASIL) is an inherited vascular dementia characterised by recurrent ischemic strokes in the deep white matter. Mutations in the gene encoding the cell surface receptor, Notch3, have been identified in CADASIL patients, and accumulation of the extracellular domain of Notch3 has been demonstrated in affected vessels. Almost all CADASIL mutations alter the number of cysteine residues in the epidermal growth factor (EGF)-like repeats in the extracellular domain of the protein.

Objectives: To understand the functional consequences of a recurrent CADASIL mutation on furin processing, cell surface expression, ligand binding, and activation of a downstream effector CBF1 by the Notch3 receptor.

Methods: We expressed wild type and mutant Notch3 receptors in cultured cells and examined cell surface expression of the proteins. We also applied a new flow cytometry based approach to semiquantitatively measure binding to three Notch ligands. Additionally, we used a well characterised coculture system to examine ligand dependent activation of transcription from a CBF1-luciferase reporter construct.

Results: These studies revealed subtle abnormalities in furin processing of the mutant receptor, although both heterodimeric and full length receptors are present on the cell surface, are capable of interacting with soluble forms of three ligands, Delta 1, Delta4, and Jagged1, and retain the ability to activate CBF1 in a ligand dependent manner.

Conclusions: By comparison with other mutant forms of Notch3, these data indicate that individual CADASIL mutations can have disparate effects on Notch3 expression and function.
\end{abstract}

surface as heterodimers composed of the transmembrane/ ICD and extracellular fragments that arise from proteolytic processing of the full length protein at the SI site by a furinlike convertase in the trans Golgi. ${ }^{13}$ The Notch ligands, Delta and Jagged, are surface associated proteins that are structurally related to Notch. Ligand binding activates a series of proteolytic cleavages at the S2 and S3 sites mediated by the metalloprotease TACE and the presenilinl/gamma secretase complex, respectively. ${ }^{14-16}$ Release of the ICD from the membrane allows it to translocate to the nucleus and activate the CSL family of transcription factors $(\mathrm{CBF} 1 / \mathrm{Su}(\mathrm{H}) /$ LAGl) (herein referred to as $\mathrm{C}$ promoter binding factor- $\mathrm{l}$ $(\mathrm{CBF} 1)),{ }^{17-22}$ leading to changes in gene expression. ${ }^{23-25}$ Although most Notch receptors present on the surface as heterodimers, a relatively small population of full length unprocessed protein is present on the surface and is capable of ligand dependent signalling via a CBFl independent pathway. $^{26}$

The extracellular domain of Notch3 contains 34 epidermal growth factor (EGF) like repeats, each with six invariant cysteine residues. Most CADASIL mutations lie within the first five EGF-like repeats, and result in either a loss or gain of a cysteine residue..$^{27-29}$ Heterozygous expression of the

Abbreviations: CADASIL, cerebral autosomal dominant arteriopathy with subcortical infarcts and leukoencephalopathy; CBF-1, C promoter binding factor-1; DMEM, Dulbecco's modified Eagle's medium; ECD, extracellular domain; EGF, epidermal growth factor; $E M$, electron microscopy; FBS, fetal bovine serum; GOM, granular osmiophilic material; HA, haemagglutinin; ICD, intracellular domain; $M I$, myocardial infarction; MRI, magnetic resonance imaging; VSMC, vascular smooth muscle cell and an extracellular domain (ECD) involved in ligand binding. They are predominantly expressed on the cell 
mutant proteins leads to attrition in functional VSMC in the arterial wall, and accumulation of the extracellular domain of Notch3 in affected vessels. ${ }^{30}$ It has been suggested that CADASIL mutations disrupt expression of the protein on the cell surface, possibly by interfering with the furin dependent processing step, ${ }^{31}{ }^{32}$ although normal surface expression of the mutant proteins has also been demonstrated..$^{33}{ }^{34}$ The notion that the mutations lead to a defect in proteolysis of the protein is based on observations of the effects of similar mutations in other proteins containing EGF-like repeats, such as fibrillin and the Notch ligand Jagged $1 .{ }^{35}{ }^{36}$ Impaired proteolysis of the mutant receptors has also been suggested by data that indicate accumulation of the Notch3 ECD in vessels undergoing the characteristic degeneration seen in CADASIL. Under EM, the GOM that is present in affected vessels shows peripheral immunoreactivity with antibodies directed to the Notch3 ECD, indicating that it is derived, at least in part, from Notch $3 .^{30}$ As proteolytic cleavage is crucial for multiple steps in Notch function, it is important to distinguish whether the increased Notch ECD immunoreactivity results from intracellular accumulation of improperly processed receptors or from impaired turnover and degradation of receptors available at the cell surface.

Expression studies indicate the presence of Notch3 and its ligands Jagged 1 and Jagged2 in VSMCs, while endothelial cells express Notch4 and Delta4. ${ }^{11}{ }^{37-39}$ Furthermore, NOTCH3 expression is downregulated in response to VSMC mitogens such as angiotensin II and platelet derived growth factor, while overexpression of a constitutively active form of Notch3 alters the proliferative capacity of cultured VSMC. ${ }^{11}$ Studies have also demonstrated that activated forms of Notchl and Notch3 enhance VSMC growth while inhibiting apoptosis and migration..$^{40}$ Recent data have further identified a role for Notch3 in arterial differentiation and VSMC maturation. ${ }^{12}$ Thus, Notch3 signalling is likely to be involved in the regulation of VSMC response to injury and stress in the adult vessel.

In this report, we identify a new CADASIL family carrying a classical cysteine substitution mutation, C185R. To clarify the effect of the mutation on receptor function, we expressed the mutant protein in culture and assayed expression of the protein on the cell surface. We show that the mutation affects the efficiency of furin dependent processing, although it does not abolish the expression of the heterodimeric receptor on the cell surface. In addition, the mutant Notch3 protein retains its capacity to bind to soluble forms of three ligands, Jagged1, Delta l, and Delta4, and to undergo ligand induced CBFl activation in response to Jagged 1 and Deltal ligands.

\section{METHODS AND MATERIALS Case presentation}

The index case was a right handed man who experienced a sudden onset of left upper extremity numbness progressing to left hemisensory deficit at 40 years of age. Additional events over subsequent years led to left hemiparesis, slurred speech, loss of balance, and personality changes including new, inappropriate cursing, and emotional lability. By 45 years of age, he had developed signs of dementia with impaired short and long term memory, and deficits in attention, insight, and judgement. He had no loss of visual acuity or symptoms of optic neuritis. Stroke risk factors included a 20 year, one pack/day smoking history and heavy alcohol use ending at 46 years of age. There was no remote or recent history of hypertension, hyperlipidaemia, diabetes, myocardial infarction (MI), or deep venous thrombosis. Physical examination revealed left sided upper motor neurone weakness of the face and upper and lower extremities. Tone was spastic on the left, with diffuse hyper-reflexia and clonus at both ankles. He had an extensor Babinski sign on the left. Primary sensory function was intact; however, cortical sensory loss was evident bilaterally. The patient had a wide, jerky gait with left circumduction.

Cardiolipin antibody was positive, but partial thromboplastin time, antithrombin III, protein C, and protein S levels were within normal limits. Erythrocyte sedimentation rate was 13; rapid plasma regain and anti-neuronal antibody titre were negative. Lipid profile, serum glucose, thyroid panel, and B12 level were within normal limits. MRI of the brain with gadolinium showed thinning of the corpus callosum and extensive, confluent, bilateral (right greater than left) periventricular white matter lesions contiguous with the frontal and occipital horns. There was also mild to moderate cerebral atrophy. Lumbar puncture was negative for biomarkers of multiple sclerosis, and visual evoked potential studies were also negative for multiple sclerosis. Carotid ultrasound showed no significant stenosis. Electron microscopy on a dermal arteriole from a skin biopsy demonstrated numerous deposits of an amorphous electron dense substance characteristic of CADASIL. Following informed consent from the patient's wife and legal representative, a blood sample was collected for mutation analysis of the NOTCH3 gene. Sequence analysis revealed a heterozygous missense mutation $631 \mathrm{~T} \rightarrow \mathrm{C}$ in exon 4 that results in the substitution of arginine for cysteine at residue 185 (C185R) in the fourth EGF-like repeat. This mutation was previously reported in an unrelated family. ${ }^{29}$

Family history (fig 1) was positive for migraine headache in the patient's mother, two of his sisters, and his niece. Following additional genetic counselling and informed consent, mutation analysis was performed for his mother and younger sister, both of whom were found to carry the C185R mutation. His mother (I-2) had mild memory loss resulting from a head injury that occurred in a car accident at the age of 71 years and stroke at 73 years. His younger sister (II-7) had several episodes of postpartum aphasia and right sided weakness beginning at 30 years of age. At the time of these events, the results of cerebral MRI and Holter monitoring were normal, and she was diagnosed with a complex migraine syndrome. There was no history of multiple sclerosis, autoimmune disease, or dementia among family members. Stroke risk factors for I-2 and II-7 included heavy tobacco use for both; however, neither had a history of hypertension, hyperlidaemia, or hyperglycaemia. The patient's father (I-1) died from MI aged 71 years.

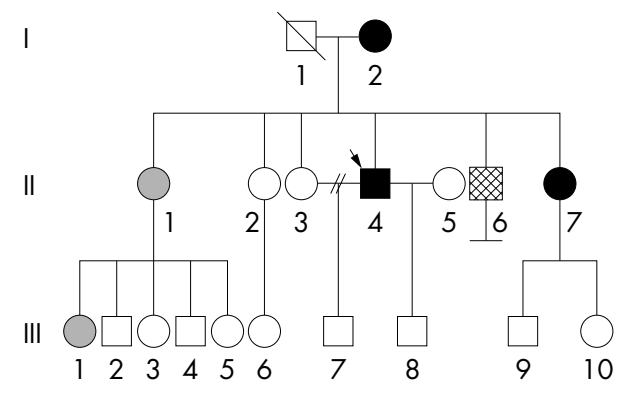

Figure 1 Pedigree of the CADASIL family. The arrow indicates the index case. Black filled symbols indicate family members who carry the C185R mutation in Notch3. Grey symbols are at risk relatives who have not been tested but have symptoms that may be CADASIL related. The hatched symbol represents an at risk person who has schizophrenia but no other known symptoms associated with CADASIL. Open symbols are relatives who have not been tested and do not have a history of CADASIL symptoms. 


\section{NOTCH3 mutation screening}

Genomic DNA was extracted from peripheral blood leukocytes using standard techniques. The $420 \mathrm{bp}$ product representing exon 4 from the NOTCH3 sequence (Genbank AF058883) was amplified using primers as previously reported. ${ }^{41}$ The PCR products were purified using Centricon columns (Millipore), sequenced by automated cycle sequencing using a PE ABI 377 automated sequencer, and analysed using PE ABI Factura (version 2.0.1) and Sequence Navigator (version 1.1) software (Applied Biosystems, Foster City, CA, USA).

\section{Cloning and mutagenesis of rat Notch 3 cDNA}

An expression construct encoding the rat Notch3 protein including a carboxyterminus triple tandem repeat haemagglutinin (HA) epitope was developed using a mammalian expression vector pEF $1 \alpha-$ BOS $^{42}$ (pBOS-N3HA) as previously described. ${ }^{33}$ Using site directed mutagenesis of the pBOSN3HA construct (QuikChange Site Directed Mutagenesis kit; Stratagene, La Jolla, CA, USA), we introduced a point mutation (C187R) into the rat Notch3 extracellular domain of EGF-like repeat 4 (analogous to human C185R).

\section{Cell culture}

We cultured 293T human embryonic kidney cells and NIH 3T3 mouse embryonic fibroblasts in Dulbecco's modified Eagle's medium (DMEM) (Invitrogen, Carlsbad, CA, USA) supplemented with $10 \%$ fetal bovine serum (Gemini BioProducts, Woodland, CA, USA), penicillin $(100 \mathrm{U} / \mathrm{ml})$, and streptomycin $(100 \mu \mathrm{g} / \mathrm{ml})$ at $37^{\circ} \mathrm{C}$ in $5 \% \mathrm{CO}_{2}$. Ltk- mouse fibroblast cells were cultured in DMEM supplemented with $5 \%$ fetal bovine serum and 5\% Cosmic calf serum (Hyclone, Logan UT, USA), penicillin $(100 \mathrm{U} / \mathrm{ml})$, and streptomycin $(100 \mu \mathrm{g} / \mathrm{ml})$ at $37^{\circ} \mathrm{C}$ in $5 \% \mathrm{CO}_{2}$.

\section{Transfection, biotinylation, and immunoblotting}

The 293T cells were transfected and biotinylated, and the biotinylated proteins were captured on streptavidin beads as previously described. ${ }^{33}$ Proteins were resolved by 6\% SDSPAGE, transferred to PVDF membranes (Millipore, Bedford, MA, USA), probed with either 1:1000 anti-HA antibody (12CA5) or 1:1000 anti-HSP90 $\beta$ (D-19; Santa Cruz Biotechnology, Santa Cruz, CA, USA), and detected with goat anti-mouse HRP (1:10 000; Jackson ImmunoResearch, West Grove, PA, USA) or rabbit anti-goat HRP (1:10 000; Jackson), respectively, and enhanced chemiluminescence (ECL-Plus; Amersham Pharmacia, Piscataway, NJ, USA). The films were scanned, and densitometry was performed on the digital images using ImageJ (version 1.32; National Institutes of Health, USA) with Fisher's exact test using GraphPad InStat (version 3.0; Graphpad Software, San Diego, CA, USA).

\section{Ligand binding assay}

Subconfluent 293T cells in 24 well dishes were transfected with pBOS-N3HA, pBOS-N3HA-C187R, or empty pBOS (50 ng+450 ng pBSKII+) using Transfast (Promega, Madison, WI, USA), then, 48 hours following transfection, the cells were blocked (blocking media: DMEM, 10\% goat serum, $1 \% \mathrm{BSA}$ ) for 1 hour at $37^{\circ} \mathrm{C}$, then incubated for 1 hour at $37^{\circ} \mathrm{C}$ with either Deltal-Fc (DlFC) or Delta4-Fc (D4FC) conditioned media or Jagged l-FC (JIFC) purified ligand (R \& D Systems, Inc, Minneapolis, MN, USA) that had been preclustered with goat anti-human Fc specific FITC conjugated antibody (Jackson Immunoresearch). DIFC and D4FC conditioned media were prepared as described. ${ }^{43}$ Similar to DlFc, D4Fc consists of the extracellular domain of mouse Delta4, fused in frame to the Fc domain of human IgG. D4FC conditioned media were concentrated 1.5-2 fold using
Centriprep centrifugal filter devices (Millipore) before use. Appropriate volumes of DIFc or D4Fc were diluted and preclustered using a 1:50 or 1:25 dilution, respectively, of the anti-FC antibody in blocking media, while JIFC was diluted to $1-3 \mu \mathrm{g} / \mathrm{ml}$ and pre-clustered using a 1:50 dilution of the antiFc antibody.

\section{Flow cytometry}

Subconfluent 293T cells in 24 well dishes were transfected and treated with soluble DIFc, D4Fc, or JlFc ligand as described above. Following incubation with ligand, cells were washed with cold buffer (PBS, 0.2\% BSA, 0.1\% sodium azide). Samples were run on a FACScaliber flow cytometer (Becton Dickinson Biosciences (BDB), San Jose, CA, USA) equipped with a $15 \mathrm{~mW} 488 \mathrm{~nm}$ air cooled argon ion laser. Using CellQuest software (BDB), 10000 events were acquired and analysed. Statistical analyses were performed using one way analysis of variance with GraphPad InStat (version 3.0).

\section{CBF 1 transactivation assay}

Subconfluent NIH 3T3 cells in six well plates were cotransfected using Transfectin transfection reagent (BioRad, Hercules, CA, USA) with 100 ng of expression constructs encoding full length receptors (N3HA or N3HA-C187R) or control vector (pBOS), along with $200 \mathrm{ng}$ of p4x wild type CBFl--luciferase reporter construct, ${ }^{18}$ and made up to $1.0 \mu \mathrm{g}$ total DNA with empty pBSKII+ vector. For normalisation of transfection,10 ng of pRLCMV Renilla luciferase expression vector was included. Then, 24 hours after transfection, cells were co-cultured with a monolayer of ligand bearing cells (Jagged 1/L, Delta 1/L, Delta4/L, or control L cells) for 24 hours as previously described. ${ }^{44}$ The Jagged 1 and Deltal expressing Ltk - cell lines have been previously described. ${ }^{43}{ }^{45}$ A stable Delta4 expressing Ltk - cell line was generated using HAT selection as previously described for Jagged l expressing cells, with the substitution of a myc epitope at the carboxy terminus. ${ }^{45}$ Cells were lysed 48 hours after transfection, and CBFl activation was monitored by levels of luciferase activity detected by luminometry using a dual luciferase assay kit (Promega). Statistical analyses were performed using one way analysis of variance with GraphPad InStat.

\section{RESULTS}

\section{Functional characterisation of mutant Notch 3}

To analyse the functional consequences of this mutation, we introduced the analogous mutation to $\mathrm{C} 185 \mathrm{R}$ into the rat Notch3 protein using site directed mutagenesis. The rat and human proteins are over $90 \%$ identical, with highest homology in the EGF-like repeats (92\% conservation). Like the human mutant allele, C187R alters the fifth cysteine residue in EGF-like repeat 4. Surface expression and proteolytic processing by the furin-like convertase were evaluated by transient expression of constructs encoding wild type (N3HA) and mutant (N3HA-C187R) Notch3 proteins in $293 \mathrm{~T}$ cells, followed by biotinylation and immunoblotting with the 12CA5 antibody directed against the carboxyterminal HA tag (fig 2A, B). Both the unprocessed full length receptor $(\sim 280 \mathrm{kDa})$ and the processed receptor (as detected by the $\sim 97 \mathrm{kDa}$ ICD) were detected in whole cell lysates (fig 2A) and streptavidin precipitates isolated from biotinylated transfected cells (fig 2B). Notably, in the whole cell lysates, there was a significant decrease in the relative abundance of the processed p97 form for N3HA-C187R compared with the wild type receptor, with the processed p97 representing $8.2 \%$ of the total signal in $\mathrm{N} 3 \mathrm{HA}-\mathrm{C} 187 \mathrm{R}$ versus $29.2 \%$ in wild type N3HA, suggesting that the mutation alters the efficiency of the furin processing step (fig 2A). This did not translate into striking differences in surface expression, 
however, as both the processed and unprocessed forms were represented among the streptavidin precipitated proteins from cells expressing wild type N3HA or N3HA-C187R (fig 2B). To control for inadvertent cell lysis during the biotinylation procedure, the streptavidin precipitated proteins were also probed with antibodies to the intracellular heat shock protein, HSP90 $\beta$. Although clearly present in the whole cell lysates (fig 2C), HSP90 $\beta$ was not detected among the biotinylated proteins (fig 2D). These data indicate that both the processed heterodimeric and full length N3HA-C187R mutant receptors are present on the surface and available for ligand interaction.

Given that the extracellular domain of Notch3 mediates ligand binding, we assessed ligand binding by the mutant protein in the 293T human embryonic kidney cell line, which expresses very little endogenous Notch receptor. These cells

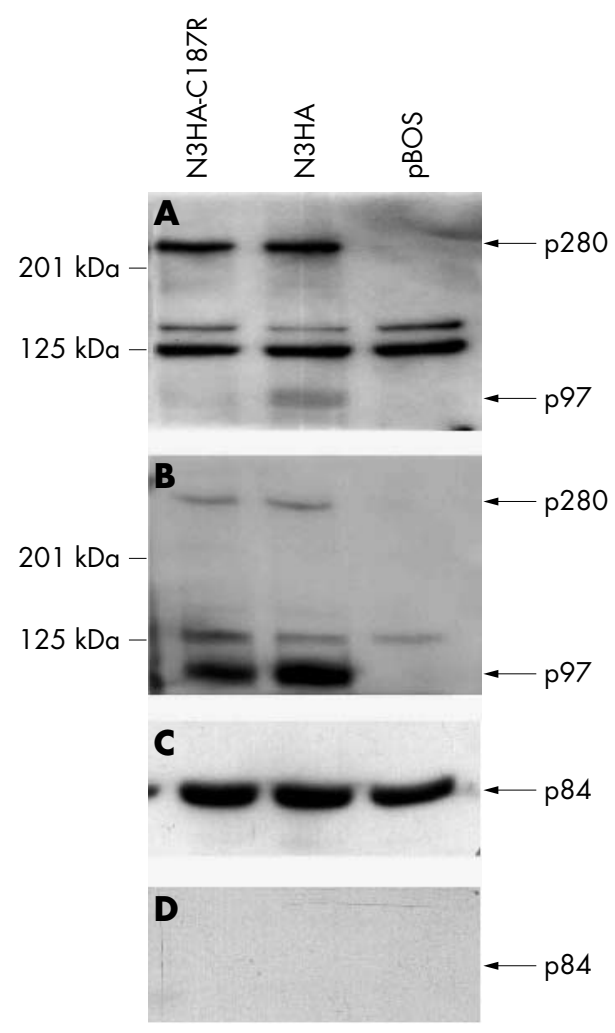

Figure 2 Expression and processing of wild type N3HA and N3HAC187R mutant proteins. (A) Expression of wild type N3HA and N3HAC187R proteins in transfected 293T cells was detected by immunoblot analysis of whole cell lysates. Antibody directed toward the $\mathrm{C}$ terminal HA epitope detected both full length $\sim$ p280 unprocessed Notch 3 protein and the processed $\sim$ p97 heterodimeric form. Densitometry analyses identify that the processed $\sim p 97$ form represents $8.3 \%$ of the total signal (p97/p280+p97) for N3HA-C187R, compared with $29.2 \%$ for wild type N3HA (Fisher's exact test, $p=0.0003$ ). No protein was detected in cells transfected with empty vector $\mathrm{pBOS}$. (B) Cell surface proteins on transiently transfected 293T live cells were labelled with biotin and captured in streptavidin beads. The antibody detected both the predominant transmembrane fragment (p97) and the full length $\sim$ p280 Notch3 protein among the biotinylated surface proteins from cells expressing wild type N3HA or mutant N3HA-C187R receptors. Densitometry analyses did not identify any difference in the relative amounts of the $\sim$ p97 processed form between wild type N3HA and mutant N3HA-C187R. No signal was detected in cells transfected with empty vector $\mathrm{pBOS}$. (C, D) To ensure that the detection of p280 and p97 in the streptavidin precipitates was not through contamination with intracellular proteins, immunoblot analysis of the intracellular p84 HSP was performed using $\alpha$-HSP90 $\beta$. Although HSP9O $\beta$ was detected in whole cell lysates from each of the transfected biotinylated cells $(C)$, it was not detected among the streptavidin precipitated proteins (D). have been used extensively in studies evaluating Notch furin processing and heterodimeric surface expression, ${ }^{13} 2631$ Notch-presenilin interactions and presenilinl induced cleavage of activated Notch, ${ }^{46-48}$ and Notch-ligand interactions. ${ }^{43}{ }^{44}$ To quantify receptor ligand interactions, we used flow cytometry to assess relative binding of the wild type and mutant Notch3 proteins. Wild type N3HA and mutant N3HAC187R proteins were transiently expressed in $293 \mathrm{~T}$ cells and tested for their ability to bind a soluble form of rat Deltal, DIFc. ${ }^{33} 434950$ Transfected cells were incubated with DIFc preclustered with anti-Fc-FITC, and ligand binding was monitored by flow cytometry using the mean level of fluorescence in the FITC channel as the indicator of relative ligand binding by the cells. In agreement with our previous observations of other mutant forms of Notch $3,{ }^{33}$ ligand binding was similar for cells expressing the wild type N3HA and N3HA-C187R proteins, indicating that the loss of a cysteine residue in the extracellular ligand binding domain does not abolish DIFC recognition and binding (fig $3 \mathrm{~A}$ ). In addition, we extended these studies to include Delta4 and Jagged l ligands. Delta4 is expressed in the arterial endothelium, while Jagged I expression has been observed in both VSMC and endothelial cells. ${ }^{113951}$ Thus, in addition to Delta 1, Delta4 and Jagged l could potentially serve as ligands for Notch3 in the vessel. Similar to Deltal, flow analyses indicated that the mutant receptor was not significantly different from the wild type receptors in terms of its avidity for the D4FC and J1FC ligands (fig 3B, C). The FITC signal is specific to ligand and Notch3 sequences because Notch3 expressing cells treated with clustered control Fc conditioned media did not exhibit any binding (data not shown).
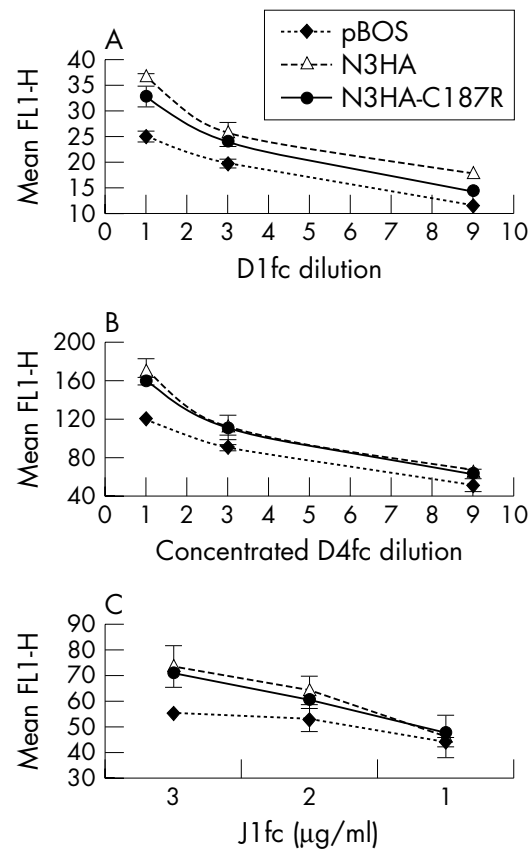

Figure $3 \mathrm{C} 187 \mathrm{R}$ mutant Notch3 protein binds soluble ligands. (A-C) 293T cells were transiently transfected with wild type N3HA (triangles) mutant C187R Notch3 (circles), or empty vector pBOS (diamonds) and incubated with various dilutions of DIFc (A) or concentrated D4Fc (B) conditioned media $(1: 1,1: 3$, or $1: 9$ dilution), or J1Fc purified ligand (1$3 \mu \mathrm{g} / \mathrm{ml})(C)$ that had been pre-clustered with anti-Fc FITC. Samples were run on a FACScaliber flow cytometer, and relative ligand binding was assessed by the levels of mean fluorescence $(F L 1-H)$ detected in the FITC channel. No significant differences in binding were detected using one way analysis of variance for the wild type N3HA or mutant receptors. Error bars reflect the standard deviation of a representative experiment performed in duplicate. 
As the C187R mutation does not abolish interactions with ligand, we examined signal transduction to establish if ligand binding by the mutant receptor translates into an ability to transmit a downstream signal. NIH 3T3 cells, widely used in evaluating Notch signal transduction via the CBFl pathway, ${ }^{24} 32344352-54$ were transiently co-transfected with constructs encoding wild type N3HA or mutant N3HA-C187R, as well as the CBFl-luciferase reporter plasmid, then cocultured with Jagged1, Deltal, or Delta4 expressing L cells. Jagged l, which has been identified as a functional ligand for Notch3 ( $\mathrm{T}$ Haritunians, unpublished observations), ${ }^{32}{ }^{34}$ is expressed by both VSMC and endothelial cells ${ }^{11}{ }^{39}$ and has been shown to be involved in vascular processes, including angiogenesis and repair. ${ }^{55}$ Although not expressed well in the vasculature, Deltal is co-expressed with Notch3 in regions of the developing brain and spinal $\operatorname{cord}^{57}$ and has been shown to interact with and activate both Notchl and Notch3. ${ }^{31} 325859$ Finally, although no functional interactions have been demonstrated between Delta4 and Notch3 to date, Delta4 is expressed in the arterial endothelium, ${ }^{39}{ }^{51}$ and thus may serve as a potentially significant ligand for Notch3 in the vasculature. Thus, we chose to evaluate CBFl activation of mutant N3HA-C187R in response to Jaggedl, Deltal, and Delta4 ligands. These studies revealed robust Jagged 1 and Delta 1 induced CBF 1 activation by both wild type Notch 3 and mutant the N3HA-C187R mutant receptor. Interestingly, while the mutant receptor activated CBFI more robustly than wild type in response to Jagged l, activation from Deltal was slightly less efficient than wild type Notch3. Delta4 was unable to induce significant activation above baseline from either wild type Notch3 or mutant N3HA-C187R (fig 4). Thus, while N3HA and N3HA-C187R exhibit ligand binding to soluble forms of all three ligands, our data suggest that Jaggedl and Deltal are more effective in inducing CBFl activation of wild type and mutant Notch3 receptors.

\section{DISCUSSION}

We describe here a new CADASIL family carrying a C185R mutation in Notch3, and we found that the analogous mutation in the rat protein does not interfere with heterodimeric cell surface expression or ligand binding. As

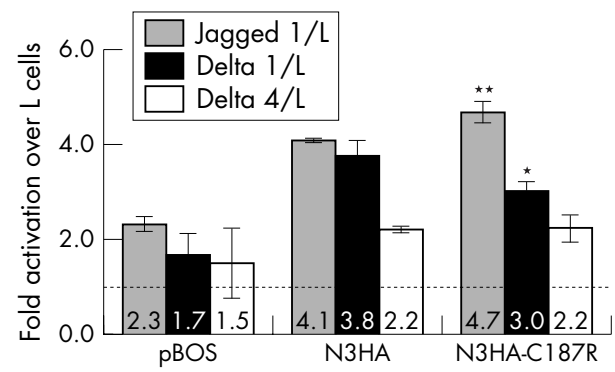

Figure 4 CBF1 activation of wild-type N3HA and N3HA-C187R mutant proteins in response to Jagged1, Deltal, and Delta4 ligands. $\mathrm{NIH}$ 3T3 cells were transiently co-transfected with plasmids encoding either wild type N3HA, N3HA-C187R, or vector only (pBOS), and $\mathrm{CBF} 1$-luciferase reporter, were co-cultured 24 hours after transfection with either Jagged1/L, Delta1/L, or Delta4/L plus parental L cells. Cell lysates were harvested 48 hours after transfection and assayed for luciferase activity. N3HA-C187R activated CBF1 more robustly than wild type when activated by Jagged $\left.1{ }^{* *} p \leqslant 0.001\right)$, but less efficiently when activated by Deltal ( $\mathrm{p} \leqslant 0.01)$. When activated by Delta 4 , both wild type N3HA and N3HA-C187R were unable to activate CBF1 above baseline. The activity measured is expressed as the fold activation induced by ligand expressing cells over that obtained with $\mathrm{L}$ cells. The dashed line at 1.0 represents activation with parental $\mathrm{L}$ cells. Error bars indicate the standard deviation of the mean from two experiments performed in duplicate.
CADASIL is a dominantly inherited disorder, it has been speculated that the mechanism of dominance of the mutations may be haploinsufficiency for Notch3 because of impaired expression of the protein as a result of defective intracellular processing. ${ }^{31}$ Arguing strongly against a haploinsufficiency mechanism is the observation that no nonsense mutations or full gene deletions have been identified in CADASIL families. Thus, it seems likely that the mechanism of dominance of CADASIL mutations may involve dominant negative effects, dominant activating effects, or, potentially, introduction of a novel function or property to the protein. ${ }^{60}$

In this report, we show that the presence of a C187R CADASIL mutation affects processing at the Sl site of the mutant protein by the furin convertase in the Golgi, although the amount of protein present on the surface does not appear to be affected (fig 2B). These data are consistent with previous reports of four other mutant rat $^{33}$ and human Notch3 forms. ${ }^{34}$ Interestingly, while levels of surface expression of both the processed heterodimeric and full length forms of the mutant receptor approximate wild type, whole cell lysate analyses identify lower amounts of the heterodimeric mutant N3HA-C187R (fig 2A). This result is similar to studies with another CADASIL mutation, R142C, which demonstrated reduced expression of the heterodimeric mutant form in favour of the full length receptor in whole cell lysates. ${ }^{31}$ However, our data do not reveal increased expression of full length mutant Notch 3 at the expense of the processed form. While the amount of processed receptor on the surface may be slightly decreased, levels of p280 detected in whole cell lysates are indistinguishable between the mutant and wild type receptors. Thus, although the C187R mutation appears to alter the efficiency of the processing step, the population of receptors on the cell surface includes both heterodimeric and full length forms.

EGF-like repeats have been shown to maintain stability and conformation. In addition, Drosophila Notch EGF-like repeats $11-12,^{61}$ corresponding to Notch3 EGF-like repeats 10-11, have been directly implicated in binding Delta and Serrate/Jagged ligands. ${ }^{32}{ }^{34}$ The roles of the remaining EGFlike repeats remain elusive; however, they appear to be involved in facilitating ligand interactions. ${ }^{62}$ Our previous study of four CADASIL-like mutations established that the mutant proteins retain the ability to recognise and bind soluble Deltal. ${ }^{33}$ Recent studies similarly evaluated binding capabilities of additional CADASIL mutants to soluble Jagged 1 and Deltal. ${ }^{32}{ }^{34}$ In agreement with these reports, we quantitatively demonstrate that although the C187R CADASIL mutation lies outside the recognised ligand binding domain, it does not enhance or reduce ligand binding by the Notch3 receptor to soluble Jagged 1, Deltal, or Delta4 (fig 3).

Having established that the presence of the C187R mutation does not interfere with surface expression of the heterodimeric receptor and binding to Deltal, Delta4, and Jaggedl ligands, we further evaluated the downstream signalling capabilities of the mutant receptor to assess possible signalling defects and potential implications on VSMC homeostasis. Our data indicate that the C187R mutation does not lead to loss of CBFl activation in response to Jagged 1 and Deltal ligands, with the mutant receptor showing evidence for increased activation. Similar studies of other CADASIL mutant forms have shown remarkable variability in signalling to CBFl from mutant Notch3 receptors, with some mutations impairing activation and others similar to wild type. ${ }^{313234}$ This is the first study demonstrating increased signalling from a CADASIL mutant receptor. Interestingly, neither wild type Notch3 nor mutant N3HA-C187R was able to activate CBFI in response to Delta4 in these cells, establishing Jaggedl and Deltal as more efficient ligands for Notch3 (fig 4). 
Studies have, however, shown dramatic accumulation of the Notch3 extracellular domain within the cerebrovasculature of CADASIL brains, suggesting impaired clearance of the Notch3 extracellular domain as a possible mechanism for CADASIL. ${ }^{30}$ Recently, it was reported that transgenic mice expressing a human CADASIL mutation also demonstrate a similar accumulation of Notch3 ECD and GOM. Morphological and pathological changes in the transgenic mice appeared to be dependent on age and were comparable with those observed in CADASIL patients. ${ }^{38}$ Dissection of the molecular pathogenesis of CADASIL should provide insight into the mechanisms underlying VSMC homeostasis in the adult vessel and ultimately provide the basis for the development of targeted therapies for this disorder. Moreover, because Notch signalling is intimately related to the activity of the gamma secretase complex including presenilin, investigations into CADASIL may have a broader impact on the understanding of adult onset dementias including Alzheimer's disease.

\section{ACKNOWLEDGEMENTS}

We are grateful to $\operatorname{Dr} \mathrm{M} \mathrm{J}$ Sobrido and $\mathrm{J}$ Johansen for their assistance. We are particularly indebted to Dr J Boulter for the cloning of rat Notch3, Dr G DiSibio for the HA tagged rat Notch3 construct and soluble DlFc ligand constructs, Dr G Bush for generating DIFc stable cell lines, and Dr K Stark and Amgen for generating soluble D4Fc. We would also like to thank the UCLA Jonsson Comprehensive Cancer Center Core (Grant \#CA-16042) and Dr I Schmid and M Gulrajani for technical assistance. This work was supported by a Bugher Stroke award from the American Heart Association (AHA 0270160N), Nemours, the Laubisch Foundation (C Schanen), the Stroke Association and Smith Charities (D M St Clair), Davidson Bequest (R P J De Lange), and a UCLA Dissertation year fellowship (T Haritunians).

\section{Authors' affiliations}

T Haritunians, N Dorrani, Departments of Human Genetics, University of California, Los Angeles, CA, USA

T Chow, The Rotman Research Institute, University of Toronto, Toronto, ON, Canada

R P J D Lange, D M S Clair, Department of Mental Health, University of Aberdeen, Medical School, Foresterhill, Aberdeen, UK

J T Nichols, G Weinmaster, Departments of Biological Chemistry, University of California, Los Angeles, CA, USA

D Ghavimi, C Schanen, Nemours Biomedical Research, Alfred I duPont Hospital for Children, Nemours Children's Clinic, Wilmington, DE, USA

\section{Competing interests: none}

This work was performed at the University of California, Los Angeles, the University of Aberdeen Medical School, and Nemours Biomedical Research at the Alfred I duPont Hospital for Children.

\section{REFERENCES}

1 Chabriat H, Vahedi K, Iba-Zizen MT, et al. Clinical spectrum of CADASIL: a study of 7 families. Cerebral autosomal dominant arteriopathy with subcortical infarcts and leukoencephalopathy. Lancet 1995;346:934-9.

2 Tournier-Lasserve E, Iba-Zizen MT, Romero N, et al. Autosomal dominant syndrome with strokelike episodes and leukoencephalopathy. Stroke 1991;22:1297-302.

3 Ruchoux MM, Guerouaou D, Vandenhaute B, et al. Systemic vascular smooth muscle cell impairment in cerebral autosomal dominant arteriopathy with subcortical infarcts and leukoencephalopathy. Acta Neuropathol (Berl) 1995;89:500-12

4 Ruchoux MM, Chabriat $\mathrm{H}$, Bousser MG, et al. Presence of ultrastructural arterial lesions in muscle and skin vessels of patients with CADASIL. Stroke 1994;25:2291-2

5 Hussain MB, Singhal S, Markus HS, et al. Abnormal vasoconstrictor responses to angiotensin II and noradrenaline in isolated small arteries from patients with cerebral autosomal dominant arteriopathy with subcortical infarcts and leukoencephalopathy (CADASIL). Stroke 2004;35:853-8.

6 Manabe Y, Murakami T, Iwatsuki K, et al. Nocturnal blood pressure dip in CADASIL. J Neurol Sci 2001;193:13-16.

7 Goate AM, Morris JC. Notch3 mutations and the potential for diagnostic testing for CADASIL. Lancet 1997:350:1490.

8 Auer DP, Putz B, Gossl C, et al. Differential lesion patterns in CADASIL and sporadic subcortical arteriosclerotic encephalopathy: MR imaging study with statistical parametric group comparison. Radiology $2001 ; 218: 443-51$.
9 Schultz A, Santoianni R, Hewan-Lowe K. Vasculopathic changes of CADASIL can be focal in skin biopsies. Ultrastruct Pathol 1999;23:241-7.

10 Joutel A, Corpechot C, Ducros A, et al. Notch3 mutations in CADASIL, a hereditary adult-onset condition causing stroke and dementia. Nature 1996:383:707-10

11 Campos AH, Wang W, Pollman MJ, et al. Determinants of Notch-3 receptor expression and signaling in vascular smooth muscle cells: implications in cellcycle regulation. Circ Res 2002;91:999-1006.

12 Domenga V, Fardoux $P$, Lacombe $P$, et al. Notch3 is required for arterial identity and maturation of vascular smooth muscle cells. Genes Dev 2004; 18:2730-5

13 Logeat F, Bessia C, Brou C, et al. The Notch 1 receptor is cleaved constitutively by a furin-like convertase. Proc Natl Acad Sci USA 1998;95:8108-12.

14 De Strooper B, Annaert W, Cupers P, et al. A presenilin-1-dependent gamma-secretase-like protease mediates release of Notch intracellular domain. Nature 1999;398:518-22.

15 Brou C, Logeat F, Gupta N, et al. A novel proteolytic cleavage involved in Notch signaling: the role of the disintegrin-metalloprotease TACE. Mol Cell 2000;5:207-16.

16 Mumm JS, Schroeter EH, Saxena MT, et al. A ligand-induced extracellular cleavage regulates gamma-secretase-like proteolytic activation of Notch 1 . Mol Cell 2000:5:197-206.

17 Fortini ME, Artavanis-Tsakonas S. The suppressor of hairless protein participates in notch receptor signaling. Cell 1994;79:273-82

18 Hsieh JJ, Henkel T, Salmon P, et al. Truncated mammalian Notch1 activates $\mathrm{CBF} 1 /$ RBPJk-repressed genes by a mechanism resembling that of Epstein-Barr virus EBNA2. Mol Cell Biol 1996;16:952-9.

19 Jarriault S, Brou C, Logeat $F$, et al. Signalling downstream of activated mammalian Notch. Nature 1995;377:355-8.

20 Lu FM, Lux SE. Constitutively active human Notch 1 binds to the transcription factor $\mathrm{CBF} 1$ and stimulates transcription through a promoter containing a CBF1-responsive element. Proc Natl Acad Sci USA 1996;93:5663-7.

21 Struhl G, Adachi A. Nuclear access and action of notch in vivo. Cell 1998:9:649-60.

22 Struhl G, Greenwald I. Presenilin is required for activity and nuclear access of Notch in Drosophila. Nature 1999;398:522-5

23 Kopan R, Nye JS, Weintraub H. The intracellular domain of mouse Notch: a constitutively activated repressor of myogenesis directed at the basic helixloop-helix region of MyoD. Development 1994;120:2385-96.

24 Nofziger D, Miyamoto A, Lyons KM, et al. Notch signaling imposes two distinct blocks in the differentiation of $\mathrm{C} 2 \mathrm{C} 12$ myoblasts. Development 1999; 126: 1689-702.

25 Nye JS, Kopan R, Axel R. An activated Notch suppresses neurogenesis and myogenesis but not gliogenesis in mammalian cells. Development 1994; 120:2421-30.

26 Bush G, diSibio G, Miyamoto A, et al. Ligand-induced signaling in the absence of furin processing of Notch1. Dev Biol 2001;229:494-502.

27 Dichgans $M$, Ludwig $\mathrm{H}$, Muller-Hocker J, et al. Small in-frame deletions and missense mutations in CADASIL: 3D models predict misfolding of Notch3 EGFlike repeat domains. Eur J Hum Genet 2000;8:280-5.

28 Kotorii S, Takahashi K, Kamimura K, et al. Mutations of the notch3 gene in non-caucasian patients with suspected CADASIL syndrome. Dement Geriatr Cogn Disord 2001;12:185-93.

29 Joutel A, Vahedi K, Corpechot C, et al. Strong clustering and stereotyped nature of Notch3 mutations in CADASIL patients. Lancet 1997;350:1511-15.

30 Joutel A, Andreux F, Gaulis S, et al. The ectodomain of the Notch3 receptor accumulates within the cerebrovasculature of CADASIL patients. J Clin Invest 2000; 105:597-605

31 Karlstrom H, Beatus P, Dannaeus K, et al. A CADASIL-mutated Notch 3 receptor exhibits impaired intracellular trafficking and maturation but normal ligand-induced signaling. Proc Natl Acad Sci USA 2002:99:171 19-24.

32 Peters N, Opherk C, Zacherle S, et al. CADASIL-associated Notch3 mutations have differential effects both on ligand binding and ligand-induced Notch3 receptor signaling through RBP-Jk. Exp Cell Res 2004;299:454-64.

33 Haritunians T, Boulter J, Hicks C, et al. CADASIL Notch3 mutant proteins localize to the cell surface and bind ligand. Circ Res 2002;90:506-8.

34 Joutel A, Monet $M$, Domenga $V$, et al. Pathogenic mutations associated with cerebral autosomal dominant arteriopathy with subcortical infarcts and leukoencephalopathy differently affect Jagged1 binding and Notch3 activity via the RBP/JK signaling Pathway. Am J Hum Genet 2004;74:338-47.

35 Morrissette JD, Colliton RP, Spinner NB. Defective intracellular transport and processing of JAG1 missense mutations in Alagille syndrome. Hum Mol Genet 2001;10:405-13.

36 Schrijver I, Liu W, Brenn T, et al. Cysteine substitutions in epidermal growth factor-like domains of fibrillin-1: distinct effects on biochemical and clinical phenotypes. Am J Hum Genet 1999;65:1007-20.

37 Iso T, Hamamori Y, Kedes L. Notch signaling in vascular development. Arterioscler Thromb Vasc Biol 2003;23:543-53.

38 Ruchoux MM, Domenga $\mathrm{V}$, Brulin $\mathrm{P}$, et al. Transgenic mice expressing mutant Notch3 develop vascular alterations characteristic of cerebral autosomal dominant arteriopathy with subcortical infarcts and leukoencephalopathy Am J Pathol 2003;162:329-42.

39 Villa N, Walker L, Lindsell CE, et al. Vascular expression of Notch pathway receptors and ligands is restricted to arterial vessels. Mech Dev 2001; 108:161-4

40 Sweeney C, Morrow D, Birney YA, et al. Notch 1 and 3 receptors modulate vascular smooth muscle cell growth, apoptosis and migration via a CBF-1/ RBP-Jk dependent pathway. FASEB J 2004;18:1421-3.

41 de Lange RP, Bolt J, Reid E, et al. Screening British CADASIL families for mutations in the NOTCH3 gene. J Med Genet 2000;37:224-5. 
42 Mizushima S, Nagata S, pEF-BOS, a powerful mammalian expression vector. Nucleic Acids Res 1990;18:5322.

43 Hicks C, Johnston SH, diSibio G, et al. Fringe differentially modulates Jagged 1 and Deltal signalling through Notch1 and Notch2. Nat Cell Biol 2000;2:515-20.

44 Hicks C, Ladi E, Lindsell C, et al. A secreted Deltal-Fc fusion protein functions both as an activator and inhibitor of Notchl signaling. J Neurosci Res 2002:68:655-67.

45 Lindsell CE, Shawber CJ, Boulter J, et al. Jagged: a mammalian ligand that activates Notch1. Cell 1995;80:909-17.

46 Ray WJ, Yao M, Nowotny P, et al. Evidence for a physical interaction between presenilin and Notch. Proc Natl Acad Sci USA 1999:96:3263-8.

47 Mizutani T, Taniguchi Y, Aoki T, et al. Conservation of the biochemical mechanisms of signal transduction among mammalian Notch family members. Proc Natl Acad Sci USA 2001;98:9026-31.

48 Ray WJ, Yao M, Mumm J, et al. Cell surface presenilin-1 participates in the gamma-secretase-like proteolysis of Notch. J Biol Chem 1999;274:36801-7.

49 Morrison SJ, Perez SE, Qiao Z, et al. Transient Notch activation initiates an irreversible switch from neurogenesis to gliogenesis by neural crest stem cells. Cell 2000;101:499-510.

50 Wang S, Sdrulla AD, diSibio $G$, et al. Notch receptor activation inhibits oligodendrocyte differentiation. Neuron 1998;21:63-75.

51 Shutter JR, Scully S, Fan W, et al. Dll4, a novel Notch ligand expressed in arterial endothelium. Genes Dev 2000;14:1313-18.

52 Rand MD, Grimm LM, Artavanis-Tsakonas S, et al. Calcium depletion dissociates and activates heterodimeric notch receptors. Mol Cell Biol 2000;20:1825-35.
53 Ross DA, Kadesch $T$. The notch intracellular domain can function as a coactivator for LEF-1. Mol Cell Biol 2001;21:7537-44.

54 Ross DA, Rao PK, Kadesch T. Dual roles for the Notch target gene Hes-1 in the differentiation of 3T3-L1 preadipocytes. Mol Cell Biol 2004; 24:3505-13.

55 Lindner V, Booth C, Prudovsky I, et al. Members of the Jagged/Notch gene families are expressed in injured arteries and regulate cell phenotype via alterations in cell matrix and cell-cell interaction. Am J Pathol $2001 ; 159: 875-83$.

56 Zimrin AB, Pepper MS, McMahon GA, et al. An antisense oligonucleotide to the notch ligand jagged enhances fibroblast growth factor-induced angiogenesis in vitro. J Biol Chem 1996;271:32499-502

57 Lindsell CE, Boulter J, diSibio G, et al. Expression patterns of Jagged, Deltal, Notch1, Notch2, and Notch3 genes identify ligand-receptor pairs that may function in neural development. Mol Cell Neurosci 1996:8:14-27.

58 Shimizu K, Chiba S, Saito T, et al. Physical interaction of Deltal, Jagged1, and Jagged 2 with Notch1 and Notch3 receptors. Biochem Biophys Res Commun 2000;276:385-9.

59 Jarriault S, Le Bail O, Hirsinger E, et al. Delta- 1 activation of notch-1 signaling results in HES-1 transactivation. Mol Cell Biol 1998;18:7423-31.

60 Donahue CP, Kosik KS. Distribution pattern of Notch3 mutations suggests a gain-of-function mechanism for CADASIL. Genomics 2004;83:59-65.

61 Rebay I, Fleming RJ, Fehon RG, et al. Specific EGF repeats of Notch mediate interactions with Delta and Serrate: implications for Notch as a multifunctional receptor. Cell 1991;67:687-99.

62 Lawrence N, Klein T, Brennan K, et al. Structural requirements for notch signalling with delta and serrate during the development and patterning of the wing disc of Drosophila. Development 2000;127:3185-95.

\section{bmjupdates+}

bmjupdates+ is a unique and free alerting service, designed to keep you up to date with the medical literature that is truly important to your practice.

bmjupdates+ will alert you to important new research and will provide you with the best new evidence concerning important advances in health care, tailored to your medical interests and time demands.

Where does the information come from?

bmiupdates+ applies an expert critical appraisal filter to over 100 top medical journals A panel of over 2000 physicians find the few 'must read' studies for each area of clinical interest

Sign up to receive your tailored email alerts, searching access and more...

www.bmjupdates.com 